\title{
Periprosthetic fracture morphology of a femoral neck prosthesis: An in vitro study
}

\author{
Stefanos Tsitlakidis' (D, Leo Vot ${ }^{2}$, Fabian Westhauser', \\ Sebastian Jaeger ${ }^{2}$ and Matthias C Klotz ${ }^{1,3}$
}

\begin{abstract}
Femoral neck prostheses have been developed for the treatment of osteoarthritis in young and active patients. The concept combines a bone-conserving and minimal invasive technique with proximal load transferring by metaphyseal anchoring, which results in a more physiological loading pattern. However, little is known about the morphology of periprosthetic fractures. Thus, the aim of this study was to describe fracture patterns and to determine patient-specific factors favoring periprosthetic fracture. This study was performed as a biomechanical experimental study using 10 fresh frozen femora and 10 Silent-Hip femoral neck implants (DePuy International Ltd., Leeds, UK). In order to simulate physiological loading, a static muscle reconstruction (abductor muscles and iliotibial band) and a dynamic simulation of the gait cycle were applied. During biomechanical testing (50\% and 100\% of normal weight-bearing), three periprosthetic fractures with two different morphologies occurred. The first pattern corresponds to an abrupt breakaway. The second type was of spiral configuration extending to the diaphyseal region and emerging from an initial fissure. Specimen-specific factors favoring periprosthetic fracture were body mass index and varus angle of the implant. Periprosthetic fractures may extend to the subtrochanteric/diaphyseal region and may be of spiral configuration. According to the finding of this study, body mass index and varus/valgus position of the implant are important factors influencing the risk of periprosthetic fractures. Furthermore, partial weight-bearing as part of the postoperative regimen may be favorable.
\end{abstract}

\section{Keywords}

Total hip arthroplasty, femoral neck prosthesis, ultra-short-stem, periprosthetic fracture morphology

Date received: 19 May 2019; accepted: 28 August 2019

\section{Introduction}

Primary total hip arthroplasty (THA) is one of the most successful surgical procedures. ${ }^{1}$ Estimations for Australia indicate an increase of $66 \%$ concerning the incidence rate (interventions per 100,000 inhabitants) of primary THA from 2013 to $2046 .^{2}$ Furthermore, the number of patients undergoing THA who are younger than 60 years is increasing and is assumed to be up to $20 \% .^{3}$ On account of the demographic change and, associated therewith, the forthcoming increase in revision rates, femoral neck prostheses have achieved importance concerning the treatment of young patients and were designed to close the gap between femoral resurfacing implants and calcar loading short-stem prostheses with partial diaphyseal anchoring. ${ }^{4-11}$ The concept combines a bone-conserving and minimal invasive technique with proximal load transferring by exclusive metaphyseal anchoring, which results in a more physiological loading pattern. ${ }^{4,12-14}$ Thus, biomechanical-associated bone atrophy ("stress shielding") is reduced. ${ }^{4,13,15}$ As a result, there is a better and bigger bone stock for future and unavoidable revision available. $^{4,14-16}$ On the contrary, there is a higher risk of periprosthetic fracture compared to the standard

\footnotetext{
'Clinic of Orthopedics \& Trauma Surgery, Heidelberg University Hospital, Heidelberg, Germany

${ }^{2}$ Laboratory of Biomechanics and Implant Research, Clinic of Orthopedics \& Trauma Surgery, Heidelberg University Hospital, Heidelberg, Germany

${ }^{3}$ Clinic for Orthopedic \& Trauma Surgery, Kepler University Hospital, Linz, Austria
}

\section{Corresponding author:}

Stefanos Tsitlakidis, Clinic of Orthopedics \& Trauma Surgery, Heidelberg University Hospital, Schlierbacher Landstr. 200a, D-69I 18 Heidelberg, Germany.

Email: stefanos.tsitlakidis@med.uni-heidelberg.de 
implants in THA. ${ }^{4,17}$ The anchoring principle itself influences the fracture risk. Press fit/cementless implanted prostheses show a higher risk than cemented implants. $^{17}$

In the past, several follow-up studies have reported partially promising results regarding mid-term survival rates of different femoral neck prostheses. ${ }^{18,19}$ Considering the possible limitations of femoral neck prostheses, long-term ( $>10$ years of follow-up) results and meta-analyses that report the outcome are necessary, still so far not existing. Especially, little is known about influencing parameters and the morphology of periprosthetic fractures after implantation of femoral neck prostheses. Therefore, the objective of this study was to analyze periprosthetic fractures in ultra-shortstem hip arthroplasties in a biomechanical in vitro study and to describe patient-specific factors favoring periprosthetic fracture.

\section{Methods}

This study was carried out as a biomechanical experimental study after approval by the local ethics committee of the Medical Faculty of the RuprechtKarls-University of Heidelberg (S-521/2010). During biomechanical testing, several periprosthetic fractures occurred. The main focus of this work was the simulation of physiological loading conditions and evaluation of periprosthetic fracture morphology. For fracture classification, the Vancouver classification system was applied.

Ten fresh frozen femora (Science Care Inc., Phoenix, AZ, USA) were used for implantation after authorization by the Institutional Review Board. The femora were obtained from three female and seven male donors. The mean age was $76.7(\mathrm{SD}=12.8)$ years $(51-$ 96 years). The mean weight was $68.4(\mathrm{SD}=21.6) \mathrm{kg}$ $(32.0-109.8 \mathrm{~kg})$, and the mean body mass index (BMI) was $23.2(\mathrm{SD}=6.4) \mathrm{kg} / \mathrm{m}^{2}\left(15.2-39.1 \mathrm{~kg} / \mathrm{m}^{2}\right)$. The mean center-collum-diaphyseal (CCD) angle was $129.8^{\circ}\left(\mathrm{SD}=8.3^{\circ}\right)\left(121.0^{\circ}-146.0^{\circ}\right)$.

Exclusion criteria were the following:

- Fracture in the past;

- Any rheumatic diseases;

- Neoplasia or chemotherapy;

- Deformity of the proximal femur;

- CCD angle less than $120^{\circ}$;

- Former infection such as HIV, HBV or HCV.

Ten Silent-Hip ${ }^{\mathrm{TM}}$ femoral neck implants (DePuy International Ltd., Leeds, UK) were used (Figure 1). The implantation was carried out according to the manufacturer's guidelines after determining the appropriate size by planning on preoperative X-rays by the same senior orthopedic surgeon, who is experienced with ultra-short-stem arthroplasty, in order to standardize

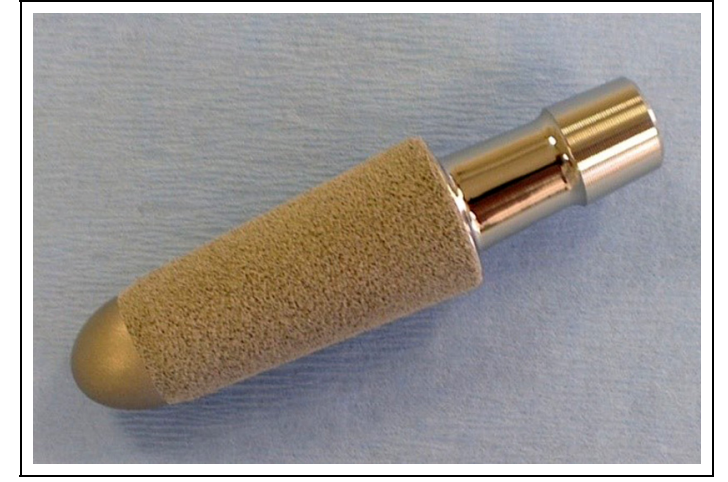

Figure I. Silent-Hip implant $(22 \times 50)$.

the implantation technique and to avoid any systematical errors. X-rays of the femur were done in anteriorposterior and axial direction before and after the surgery. Used implant sizes (diameter $(\mathrm{mm}) \times$ length $(\mathrm{mm})$ were $22 \times 45$ (1), $22 \times 50$ (2), $22 \times 50$ (3), $24 \times 50$ (2), $24 \times 60$ (1) and $26 \times 60$ (1). Postoperatively, varus and valgus position of the implant in relation to the CCD angle was measured using the relative implantation angle (relative implantation angle $=$ implantation angle of the prosthesis-CCD). A negative relative implantation angle indicates a varus position of the implant.

Specimen fixation was realized using synthetic resin (RENCAST $^{\circledR}$ FC53 A/B; Goeß1 \& Pfaff, Munich, Germany). The fixation depth of the specimen was one-sixth of femur length.

Moreover, in order to simulate a physiological loading pattern, a dynamic simulation of the gait cycle was achieved using a self-made hip kinemator (Figure 2) that reproduced the vector loop of the hip contact force, with cyclic application of forces in $x, y$ and $z$ axes relative to the hip joint, as described by Bergmann et al. and others. ${ }^{20-27}$ Cyclic application of forces was realized by the rocker ( 2 in Figure $2 b$ ), the swing ( 3 in Figure $2 b$ ) and the integrated loading cylinder ( 1 in Figure $2 \mathrm{~b}$ ). The rocker and swing moved the loading cylinder in all three dimensions controlled via angle sensors (e.g. 4 in Figure 2b). The loading cylinder then applied the hip contact force (controlled via an integrated force sensor ( 5 in Figure $2 b$ )) via an integrated acetabular cup to the head of the prostheses. Raw data were taken from Bergmann's ${ }^{28}$ HIP98 dataset. This dataset contains information on the acting forces of the hip joint during activities such as walking or stair climbing. Originally, data were generated using measurement devices which were integrated into the hip implants and using additional three-dimensional gait analysis. Obtained loads were adjusted to the weight of the different donors. Biomechanical testing was carried out at $50 \%(n=6)$ and $100 \%(n=4)$ load of individual body weight subsequently, which correlates to hip contact forces of $8 \%$ (minimum under partial weightbearing) up to $262 \%$ body weight (maximum under full weight-bearing; Figure 3) with a frequency of $1 \mathrm{~Hz}$ for 


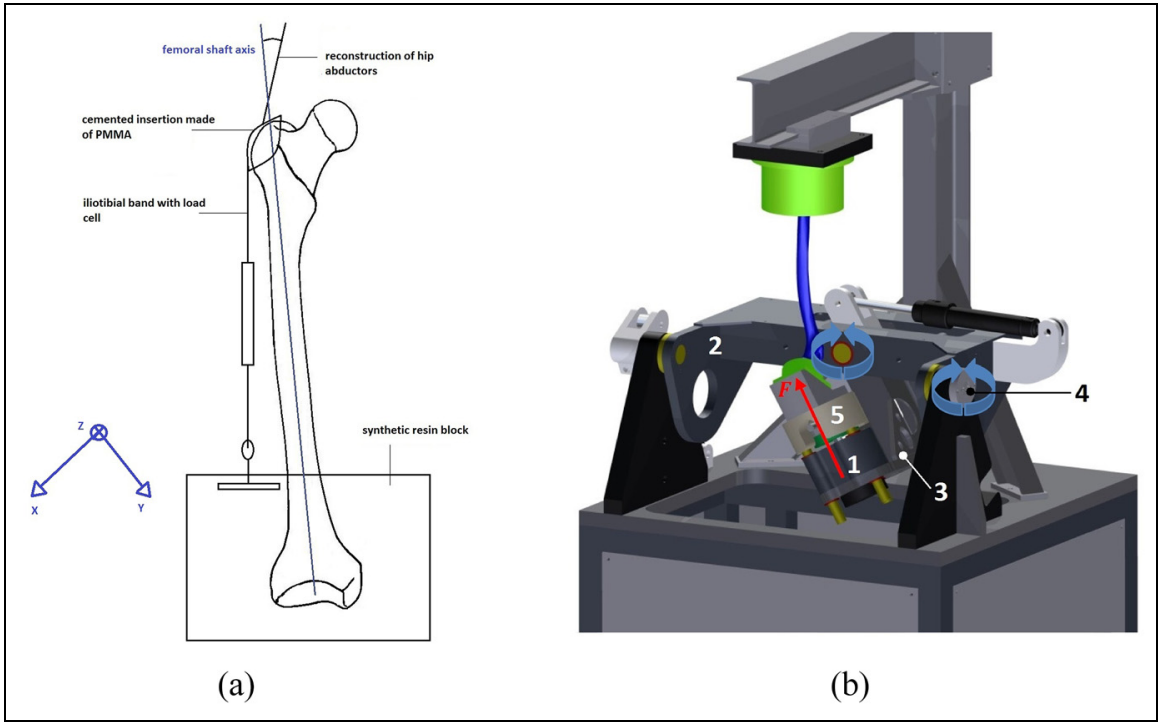

Figure 2. (a) Sketch of a prepared specimen with resin fixation and muscle reconstruction and applied coordinate system; (b) selfmade hip kinemator (I, hydraulic loading cylinder; 2, rocker; 3, swing; 4, angle sensor; 5 , integrated force sensor).

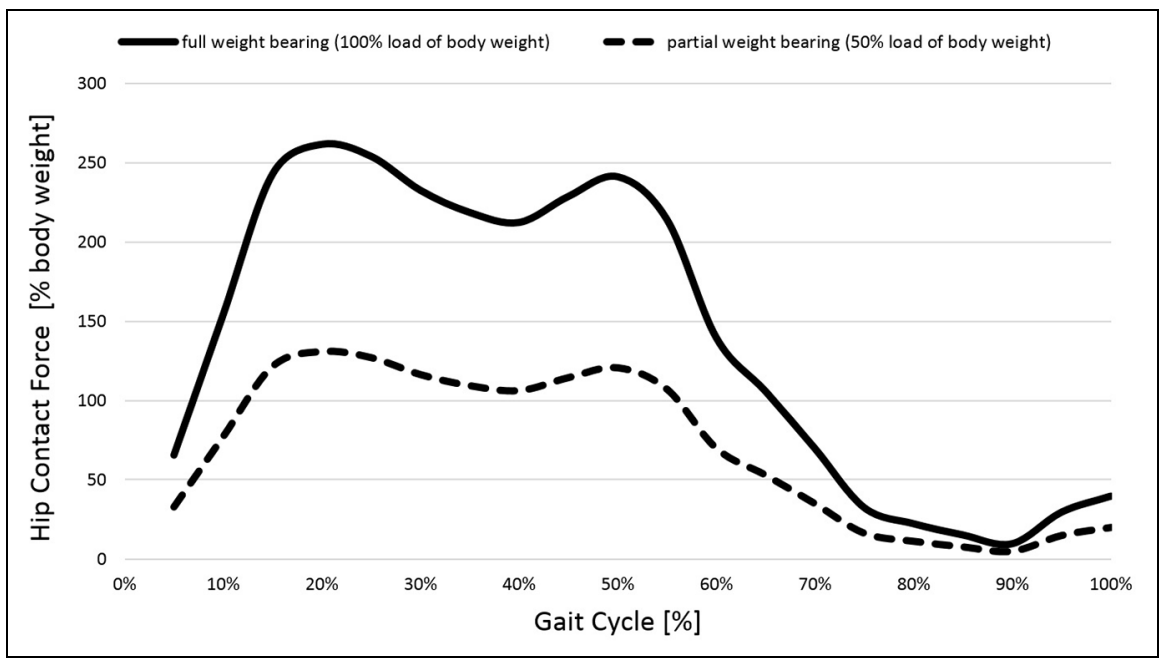

Figure 3. Hip contact forces for dynamic simulation of the gait cycle.

1000 cycles. In total, absolute values for hip contact forces ranged from $256 \mathrm{~N}$ to $28.8 \mathrm{kN}$.

Furthermore, in order to complete physiological loading, a static reconstruction of the abductor muscles (Mm. glutei and M. tensor fascia lata) and the iliotibial band was realized. For this, a 2-mm cable wire was used (Figure 2a). The abductor muscles were attached to the greater trochanter at an angle of $20^{\circ}$ to the femoral shaft axis in frontal plane. ${ }^{29}$ Individualized and weightadjusted muscle forces were determined according to the values outlined by Bergmann et al..$^{20-22,28}$ The corresponding weights for the abductor muscles were applied to the cable wire. Corresponding and individual forces for the static reconstruction of the iliotibial band were applied via a manual mechanic clamping system and controlled by an integrated load cell (Figure $2 \mathrm{a}$ ). Table 1 shows the donor-specific forces of the abductor
Table I. Donor specific forces for static muscle reconstruction.

\begin{tabular}{lllll}
\hline Specimen & $\begin{array}{l}\text { Weight } \\
(\mathrm{kg})\end{array}$ & $\begin{array}{l}\text { Loading } \\
\text { (\% of body } \\
\text { weight) }\end{array}$ & $\mathrm{F}_{\mathrm{ABD}}(\mathrm{N})$ & $\mathrm{F}_{\text {ITB }}(\mathrm{N})$ \\
\hline 1 & 90 & 50 & 346 & 84 \\
2 & 54 & 100 & 416 & 101 \\
3 & 72 & 100 & 553 & 134 \\
4 & 74 & 100 & 570 & 138 \\
5 & 86 & 50 & 332 & 80 \\
6 & 57 & 50 & 217 & 52 \\
7 & 59 & 50 & 225 & 54 \\
8 & 110 & 50 & 422 & 102 \\
9 & 49 & 100 & 374 & 91 \\
10 & 32 & 50 & 123 & 30 \\
\hline
\end{tabular}

$\mathrm{F}_{\mathrm{ABD}}$ : forces of abductor muscles; $\mathrm{F}_{\mathrm{ITB}}$ : forces of iliotibial band. 


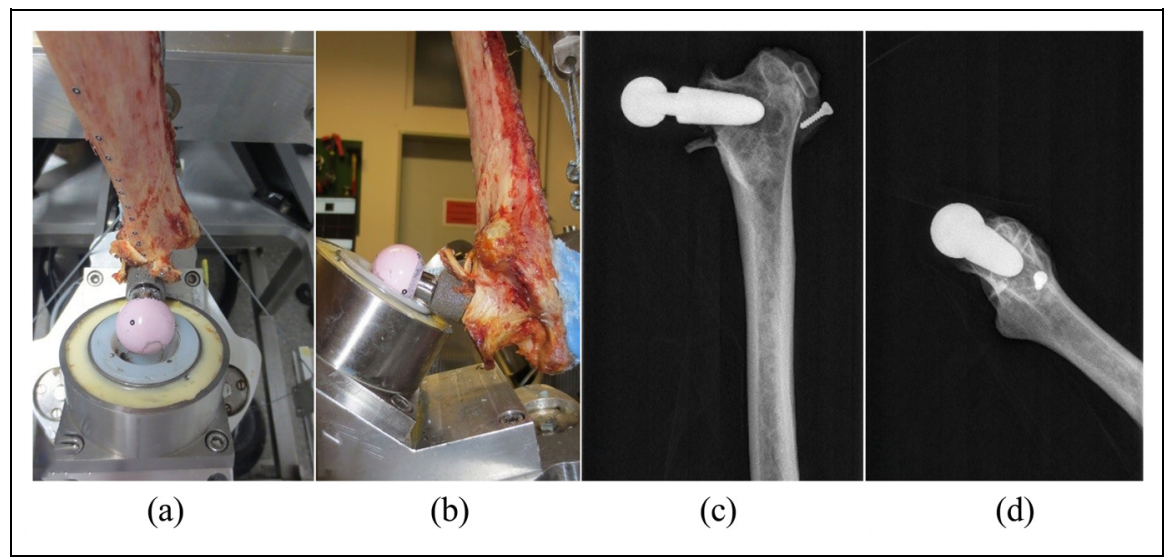

Figure 4. First periprosthetic fracture from (a) medial and (b) posterior direction; X-rays in (c) anterior-posterior and (d) mediolateral plane.

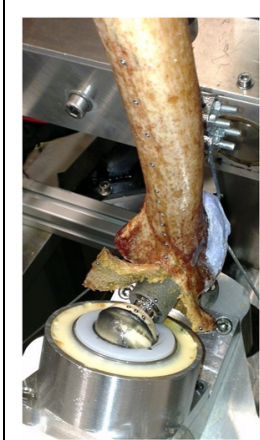

(a)

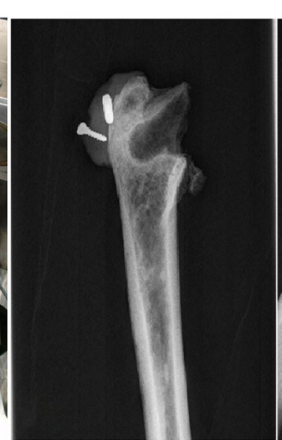

(b)

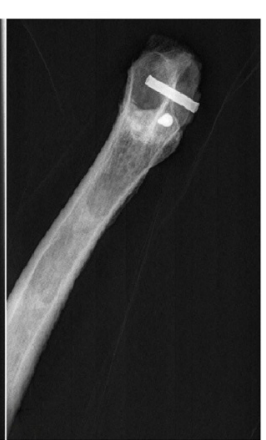

(c)
Figure 5. Second periprosthetic fracture from (a) anteromedial direction; X-rays in (b) anterior-posterior and (c) mediolateral plane.

muscle and iliotibial band reconstruction with absolute values.

For real-time imaging during biomechanical testing, the PONTOS System of Gesellschaft fuer Optische Messtechnik (GOM mbH, Braunschweig, Germany) was used.

\section{Statistics}

Raw data were structured using Microsoft Excel 2013 (Microsoft, Redmond, WA, USA) and analyzed using SPSS Version 21.0 (IBM, Chicago, IL, USA). For descriptive statistics, the mean and the standard deviation were calculated. For interferential statistics, the two-tailed Student's $t$-test and chi-square test were performed. The level of significance was set at $p<0.05$.

\section{Results}

During biomechanical testing, three periprosthetic fractures occurred. According to the Vancouver classification, all the three periprosthetic fractures were type B2 fractures. ${ }^{30}$

The first periprosthetic fracture occurred suddenly under $50 \%$ load of physiological weight-bearing at cycle 156 (Figure 4). The BMI of the donor was $39.07 \mathrm{~kg} / \mathrm{m}^{2}$, bone mineral density (BMD) (femoral neck) was $0.765 \mathrm{~g} / \mathrm{cm}^{2}, \mathrm{CCD}$ angle was $120.8^{\circ}$, relative implantation angle was $-7.3^{\circ}$ and used implant size was $22 \times 45$.

The second periprosthetic fracture occurred under $100 \%$ of physiological weight-bearing at cycle 4 (Figure 5). The BMI of the donor was $24.13 \mathrm{~kg} / \mathrm{m}^{2}$, BMD (femoral neck) was $0.575 \mathrm{~g} / \mathrm{cm}^{2}$, CCD angle was $131.2^{\circ}$, relative implantation angle was $-6.1^{\circ}$, and used implant size was $24 \times 50$.

The third and last periprosthetic fracture occurred under $100 \%$ of physiological weight-bearing at cycle 192 (Figure 6). It emerged from an initial fissure in the medial femoral neck area (Figure 7). The BMI of the donor was $23.49 \mathrm{~kg} / \mathrm{m}^{2}$, BMD (femoral neck) was $0.604 \mathrm{~g} / \mathrm{cm}^{2}, \mathrm{CCD}$ angle was $137.4^{\circ}$, relative implantation angle was $-9^{\circ}$ and used implant size was $22 \times 60$. Table 2 provides all analyzed donor-specific parameters.

Specimens that were affected by periprosthetic fracture showed a mean age of $71.3 \pm 8.5$ years, mean height of $172.7 \pm 4.2 \mathrm{~cm}$, mean weight of $85.4 \pm 17.3 \mathrm{~kg}$, mean BMI of $28.9 \pm 7.2 \mathrm{~kg} / \mathrm{m}^{2}$, mean BMD of $0.65 \pm 0.1 \mathrm{~g} / \mathrm{cm}^{2}$, mean CCD angle of $129.8 \pm 6.9^{\circ}$ and mean relative implantation angle of $-7.5 \pm 1.2^{\circ}$.

The non-fracture group was characterized by a mean age of $79.0 \pm 13.6$ years, mean height of $169.5 \pm 15.3 \mathrm{~cm}$, mean weight of $61.1 \pm 19.1 \mathrm{~kg}$, mean BMI of $20.8 \pm 4.1 \mathrm{~kg} / \mathrm{m}^{2}$, mean BMD of $0.63 \pm$ $0.1 \mathrm{~g} / \mathrm{cm}^{2}$, mean CCD angle of $129.3 \pm 9.0$ and mean relative implantation angle of $-3.0 \pm 6.5^{\circ}$.

There was no statistically significant difference $(p>0.05)$ between the fractured and non-fractured group regarding all analyzed donor-specific parameters 
Table 2. Donor-specific parameters.

\begin{tabular}{|c|c|c|c|c|c|c|c|c|c|c|}
\hline Specimen & Sex & $\begin{array}{l}\text { Age } \\
\text { (years) }\end{array}$ & $\begin{array}{l}\text { Height } \\
(\mathrm{cm})\end{array}$ & $\begin{array}{l}\text { Weight } \\
(\mathrm{kg})\end{array}$ & $\begin{array}{l}\mathrm{BMI} \\
\left(\mathrm{kg} / \mathrm{m}^{2}\right)\end{array}$ & $\begin{array}{l}\text { BMD } \\
\left(\mathrm{g} / \mathrm{cm}^{2}\right)\end{array}$ & $\begin{array}{l}\text { CCD } \\
\text { angle }\left({ }^{\circ}\right)\end{array}$ & $\begin{array}{l}\text { Relative } \\
\text { implantation } \\
\text { angle }\left(^{\circ}\right)\end{array}$ & $\begin{array}{l}\text { Loading } \\
\text { (\% of body } \\
\text { weight) }\end{array}$ & $\begin{array}{l}\text { Implant size: } \\
\text { diameter } \times \\
\text { length }(\mathrm{mm})\end{array}$ \\
\hline \multicolumn{11}{|l|}{ Fractured } \\
\hline 3 & $M$ & 76 & 173 & 72 & 24.1 & 0.58 & 131.2 & -6.1 & 100 & $24 \times 50$ \\
\hline 4 & $M$ & 79 & 178 & 74 & 23.5 & 0.60 & 137.4 & -9.0 & 100 & $22 \times 60$ \\
\hline 8 & $\mathrm{~F}$ & 59 & 168 & 110 & 39.1 & 0.77 & 120.8 & -7.3 & 50 & $22 \times 45$ \\
\hline Mean & & 71.3 & 172.7 & 85.4 & 28.9 & 0.65 & 129.8 & -7.5 & & \\
\hline SD & & 13.5 & 4.2 & 17.3 & 7.2 & 0.1 & 6.9 & 1.2 & & \\
\hline \multicolumn{11}{|l|}{ Non-fractured } \\
\hline 1 & $M$ & 69 & 188 & 90 & 25.5 & 0.85 & 146.0 & -11.0 & 50 & $24 \times 50$ \\
\hline 2 & $M$ & 85 & 178 & 54 & 17.1 & 0.74 & 129.1 & -6.0 & 100 & $24 \times 60$ \\
\hline 5 & $M$ & 84 & 178 & 86 & 27.3 & 0.61 & 127.5 & -5.5 & 50 & $26 \times 60$ \\
\hline 6 & $M$ & 51 & 175 & 57 & 18.6 & 0.63 & 136.2 & -8.6 & 50 & $22 \times 50$ \\
\hline 7 & $M$ & 85 & 176 & 59 & 19.1 & 0.70 & 126.9 & 6.7 & 50 & $24 \times 50$ \\
\hline 9 & $\mathrm{~F}$ & 96 & 147 & 49 & 22.4 & 0.52 & 124.7 & -3.0 & 100 & $22 \times 50$ \\
\hline 10 & $\mathrm{~F}$ & 83 & 145 & 32 & 15.2 & 0.37 & 114.9 & 6.4 & 50 & $22 \times 50$ \\
\hline Mean & & 79.0 & 169.5 & 61.1 & 20.8 & 0.63 & 129.3 & -3.0 & & \\
\hline SD & & 13.6 & 15.3 & 19.1 & 4.1 & 0.1 & 9.0 & 6.5 & & \\
\hline $\begin{array}{l}\mathrm{P} \text { value (fractured vs } \\
\text { non-fractured) }\end{array}$ & & 0.4 & 0.7 & 0.15 & 0.08 & 0.84 & 0.94 & 0.2 & & \\
\hline
\end{tabular}

BMI: body mass index; BMD: bone mineral density; CCD: center-collum-diaphyseal.

Negative values for the relative implantation angle indicate varus position.

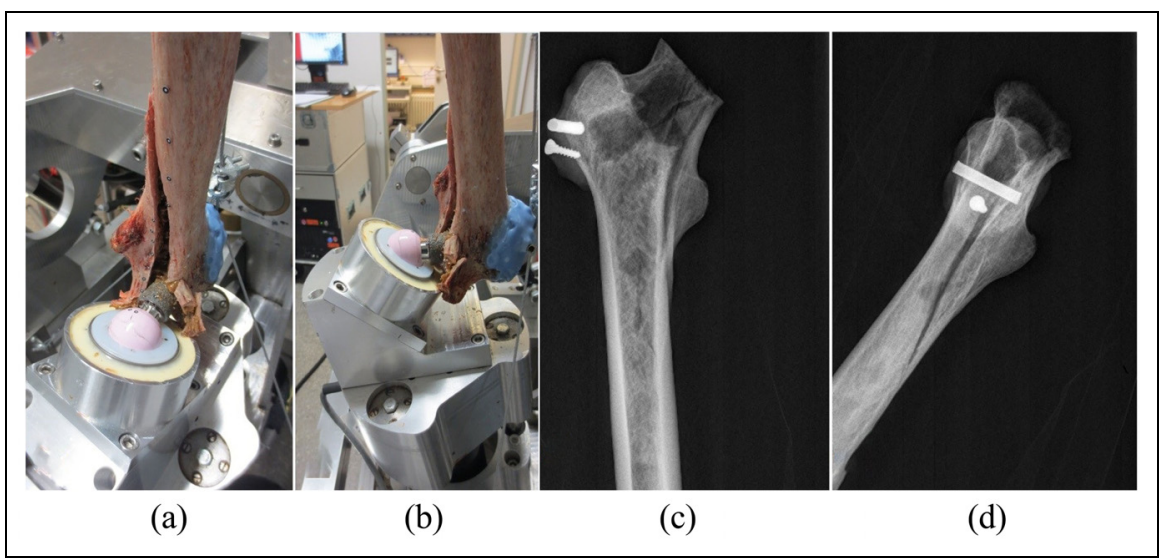

Figure 6. Third periprosthetic fracture from (a) anterio-medial and (b) anterior direction; X-rays in (c) anterior-posterior and (d) medio-lateral plane.

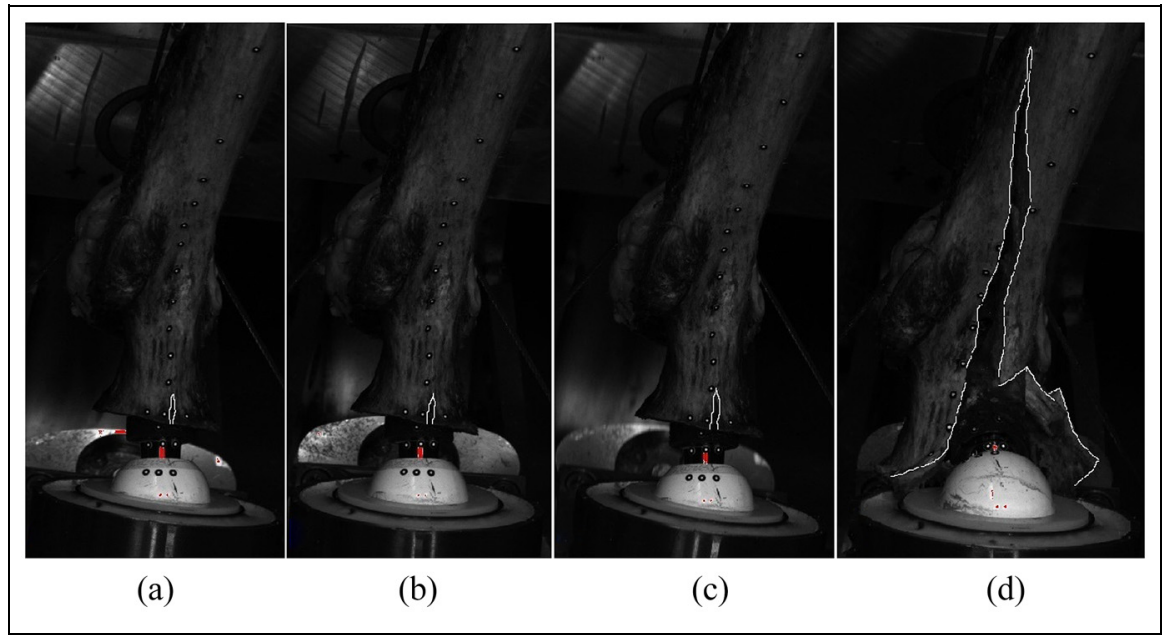

Figure 7. (a-d) Image series of emerging fracture from an initial fissure. 
(Table 2). Chi-square test revealed no statistically significant difference regarding the incidence under $50 \%$ load of body weight versus $100 \%$ load of body weight $(p=0.26)$.

\section{Discussion}

Femoral neck prostheses have been developed for the treatment of osteoarthritis of younger and active patients. ${ }^{7}$ However, in the literature, there are only few biomechanical studies investigating femoral neck prostheses. In particular, little is known about the morphology of periprosthetic fractures after implantation of femoral neck prostheses and influencing parameters. The objective of this study was to describe possible fracture patterns and patient-specific factors favoring periprosthetic fractures using femoral neck prostheses.

The focus of the study was initially not limited to periprosthetic fractures, specifically their morphology. The purpose of this investigation was to evaluate the biomechanical behavior of a femoral neck prosthesis (Silent-Hip) under physiological (partial and full weight-bearing) loading conditions. In this context, a new biomechanical setup with emphasis on dynamic gait simulation and muscle reconstruction as a key aspect was used rather than applying uniaxial force until occurrence of periprosthetic fracture. Knowing that this biomechanical approach leads to a restricted number of periprosthetic fractures as a limitation, it allows direct comparison of fractured and nonfractured specimens under the same conditions and thus detecting patient-specific parameters that might have influence on fracture risk. However, in this study, the observed periprosthetic fractures and patientspecific parameters were analyzed in particular. A further limitation of this study is the limited sample size. The sample size in this study is limited as cadaver bones are difficult to obtain in large numbers. Furthermore, cadaver bones used were those of elderly persons since bones from young individuals are not generally obtainable. In order to closely mimic physiological conditions, cadaver bones were used rather than synthetic femora, knowing that the bones might be affected by age concerning bone quality and mechanical behavior. However, implantation of femoral neck prostheses is generally performed on younger patients, so the results obtained in this study are not entirely representative of the clinical situation.

Positive aspects of this study are nevertheless the use of fresh frozen femora than the use of synthetic femora as well as the simulation of physiological gait cycle and the application of simulated attached muscles to more closely mimic the clinical situation. To our knowledge, gait simulation and muscle reconstruction have not been realized to this extend in the past.

Surprisingly, despite sample sizes of 4-6 and lack of statistical significance, there was a high incidence of periprosthetic fractures seen that all would have led to surgical revision. In total, 3 of the 10 specimens showed a periprosthetic fracture during biomechanical testing. The incidence of periprosthetic fractures was higher under $100 \%$ of physiological weight-bearing $(n=2$, $50 \%$ of all specimens under full weight-bearing) than under $50 \%$ of physiological weight-bearing $(\mathrm{n}=1$, $17 \%$ of all specimens under $50 \%$ weight-bearing). This fracture incidence of $30 \%$ is considerably higher than the reported fracture incidence of $1.2 \%(66 \%$ of all revisions) by McMinn et al. ${ }^{10}$ during their clinical 3.5year-follow-up study of the Birmingham Mid Head Resection (BMHR) prosthesis. The observed periprosthetic fractures occurred under full weight-bearing postoperatively, leading to a change in postoperative regimen re-establishing $50 \%$ partial weight-bearing for 4 weeks after surgery, thus suggesting that partial weight-bearing should be favored. ${ }^{10}$ To our knowledge, other authors did not observe periprosthetic fractures. ${ }^{18}$ Main complication was aseptic loosening. ${ }^{31,32}$ In addition, Ries et al. ${ }^{33}$ successfully applied a postoperative regime with partial weight-bearing $(50 \%$ of body weight) for 4 weeks. After the first 4 weeks after surgery, they increased weight-bearing gradually. ${ }^{33}$ Our findings suggest that even a postoperative regime with less than $50 \%$ of normal weight-bearing should be favored.

In this context, the anchoring principle itself influences the fracture risk. Press fit/cementless implanted prostheses show a higher risk than cemented implants. $^{17}$

Furthermore, two fracture patterns could be detected from this case study. The first pattern was equivalent to an abrupt breakaway of the prosthesis affecting the medial cortex of the femoral neck (Figures 4 and 5). This pattern resulted when fracture occurred abruptly and would have led to surgical revision under clinical conditions due to instability and implant migration. The second fracture pattern is equivalent to an initial small fissure that emerged to a spiral fracture under further loading, reaching to the subtrochanteric dorsal region (Figures 6 and 7). Under clinical conditions, this emerging spiral fracture would have also caused implant loosening, making surgical revision necessary. Both fracture patterns would occur the first day after surgery as they occurred on cycles 4, 156 and 192 during biomechanical testing. The second pattern with a spiral configuration has been observed by Aqil et al. ${ }^{34}$ In their case report, the fracture reached the subtrochanteric/diaphyseal region of the femur as well. ${ }^{34}$ However, the implanted prosthesis was the BMHR prosthesis. $^{34}$ Aghayan et al. and Olsen et al. observed similar fracture patterns during their biomechanical investigations using the BMHR prosthesis. ${ }^{5,8,34,35}$

The main distinctive factors of femoral neck (only) prostheses compared to conventional short-stem implants are the exclusive metaphyseal anchoring/ femoral neck fixation. ${ }^{4,11}$ In contrast to conventional short-stem implants, no fixation is achieved laterally. ${ }^{4}$ Primary stability is realized through compression of the cancellous bone. ${ }^{4}$ Due to this circumstance and the 
naturally eccentric positioning compared to the hip contact force, femoral neck prostheses are subject to varus torque.

Ries et al. ${ }^{33}$ described that a varus angle of a femoral neck prosthesis (Silent-Hip) - and thus the varus torque - can increase when there is a small CCD angle, leading to further varisation of the implant. Regarding the donor-specific factors (Table 2), it is noticeable that all specimens that were affected by a periprosthetic fracture show a varus angle of the implant. The mean varus angle in the fracture group $\left(-7.5^{\circ}\right)$ was twice as high as in the non-fracture group $\left(-3.0^{\circ}\right)$. The specimen of the first periprosthetic fracture showed a varus angle of $113.5^{\circ}\left(-7.3^{\circ}\right)$, the second specimen a varus angle of $125.1^{\circ}\left(-6.1^{\circ}\right)$ and the third specimen a varus angle of $128.4^{\circ}\left(-9^{\circ}\right)$. In this context, Aqil et al. and Olsen et al. concluded that a valgus angle is protective against the occurrence of periprosthetic fractures.,34 A valgus angle is beneficial on account of increased compressive forces and simultaneously reduced shear forces in the femoral neck. ${ }^{5}$ Thus, a valgus angle should be striven for. Our results suggest that at least a neutral relative implantation angle (avoiding varus positioning) is favorable to reduce periprosthetic fracture risk (Table 2).

Furthermore, BMD of the femoral neck has been described to highly correlate with fracture load. ${ }^{5,17}$ The authors therefore concluded that BMD of the femoral neck could be used as a prognostic factor concerning periprosthetic fracture. ${ }^{5}$ In contrast, our results show no statistical differences between the fractured and nonfractured specimens (Table 2); this might be caused due to the small sample size.

Regarding the implant size, Olsen et al. ${ }^{5,8}$ found a negative correlation of implant size and fracture load and concluded that using small implants is advantageous, whereas Aghayan et al. ${ }^{36}$ found higher fracture loads using bigger implant sizes. Used implants during our biomechanical evaluation where of different sizes (Silent $22 \times 45$ (small); Silent $24 \times 50$ (medium); Silent $22 \times 60$ (big)). There was no difference regarding implant size between the fracture and non-fracture group. Our findings do not allow any recommendation regarding the implant size.

Considering the BMI, the first affected specimen showed a high BMI of the donor $\left(39.1 \mathrm{~kg} / \mathrm{m}^{2}\right)$, leading to high forces during biomechanical testing. Furthermore, the mean BMI in the fracture group $\left(28.9 \pm 7.2 \mathrm{~kg} / \mathrm{m}^{2}\right)$ was considerably higher compared to the non-fracture group $\left(20.8 \pm 4.1 \mathrm{~kg} / \mathrm{m}^{2}\right)$. Jakubowitz et al. ${ }^{17}$ reported positive correlation between the BMI and fracture risk. The bone-implant interface is subject to higher loads. ${ }^{17}$ As the upper limit of the BMI in the non-fractured group (mean $+\mathrm{SD}$ ) was $24.9 \mathrm{~kg} / \mathrm{m}^{2}$ (Table 2), a BMI of less than $25 \mathrm{~kg} / \mathrm{m}^{2}$ is reasonable. Even though due to the sample size no statistically significant difference could be found, both groups showed most noticeable differences regarding the BMI (Table 2).
All further recorded donor-specific factors did not show a statistically significant difference to those of the intact specimens.

In conclusion, the morphology of periprosthetic fractures of an implanted femoral neck prosthesis seems to be diverse. Periprosthetic fractures may extend to the subtrochanteric/diaphyseal region and may be of spiral configuration. BMI and varus angle of the implant are factors that might influence the risk of periprosthetic fractures. Therefore, in order to minimize fracture risk, an implantation in valgus angle should be striven for. Furthermore, a postoperative regimen with partial weight-bearing seems to be favorable.

\section{Acknowledgements}

Essential participation in the conception and design of the study as well as acquisition, analysis and interpretation of data were done by all authors. The manuscript was edited and approved by all mentioned authors. We particularly thank Prof. Dr med. Christian Heisel for his contribution to our project.

\section{Declaration of conflicting interests}

The author(s) declared the following potential conflicts of interest with respect to the research, authorship, and/ or publication of this article: SJ has received research support as a Principal Investigator from Johnson \& Johnson DePuy, B Braun Aesculap, Waldemar Link, Heraeus Medical, and Zimmer Biomet. ST, LV, FW and MK declare that they have no conflict of interest.

\section{Ethical approval}

This study was approved by the local ethics committee of the Medical Faculty of the Ruprecht-KarlsUniversity of Heidelberg (S-521/2010).

\section{Funding}

The author(s) received no financial support for the research, authorship, and/or publication of this article.

\section{ORCID iD}

Stefanos Tsitlakidis https://orcid.org/0000-0002$0547-4630$

\section{References}

1. Learmonth ID, Young C and Rorabeck C. The operation of the century: total hip replacement. Lancet 2007; 370: $1508-1519$.

2. Inacio MCS, Graves SE, Pratt NL, et al. Increase in total joint arthroplasty projected from 2014 to 2046 in Australia: a conservative local model with international implications. Clin Orthop Relat Res 2017; 475: 2130 2137.

3. Jerosch J. Is shorter really better? Philosophy of short stem prosthesis designs. Orthopade 2011; 40: 1075-1083. 
4. Khanuja HS, Banerjee S, Jain D, et al. Short boneconserving stems in cementless hip arthroplasty. $J$ Bone Joint Surg Am Vol 2014; 96: 1742-1752.

5. Olsen M, Al Saied M, Morison Z, et al. The impact of proximal femoral morphology on failure strength with a mid-head resection short-stem hip arthroplasty. Proc IMechE Part H: J Engineering in Medicine 2014; 228: $1275-1280$.

6. Thomas W, Lucente L, Mantegna N, et al. ESKA (CUT) endoprosthesis. Orthopade 2004; 33: 1243-1248.

7. Eichinger SFR and Kindervater M. Indikationen und Alternativen der endoprothetischen Versorgung beim jüngeren Patienten. Orthopäde 2007; 36: 311-324.

8. Olsen M, Sellan M, Zdero R, et al. A biomechanical comparison of epiphyseal versus metaphyseal fixed boneconserving hip arthroplasty. J Bone Joint Surg Am Vol 2011; 93(Suppl. 2): 122-127.

9. Dabirrahmani D, Hogg M, Kohan L, et al. Primary and long-term stability of a short-stem hip implant. Proc IMechE Part H: J Engineering in Medicine 2010; 224: 1109-1119.

10. McMinn DJ, Pradhan $\mathrm{C}$, Ziaee $\mathrm{H}$, et al. Is mid-head resection a durable conservative option in the presence of poor femoral bone quality and distorted anatomy? Clin Orthop Relat Res 2011; 469: 1589-1597.

11. van Oldenrijk J, Molleman J, Klaver M, et al. Revision rate after short-stem total hip arthroplasty: a systematic review of 49 studies. Acta Orthop 2014; 85: 250-258.

12. Arno S, Fetto J, Nguyen NQ, et al. Evaluation of femoral strains with cementless proximal-fill femoral implants of varied stem length. Clin Biomech 2012; 27: 680-685.

13. Salemyr M, Muren O, Ahl T, et al. Lower periprosthetic bone loss and good fixation of an ultra-short stem compared to a conventional stem in uncemented total hip arthroplasty. Acta Orthop 2015; 86: 659-666.

14. Steens W, Boettner F, Bader R, et al. Bone mineral density after implantation of a femoral neck hip prosthesisa prospective 5 year follow-up. BMC Musculoskelet Disord 2015; 16: 192.

15. Steinhauser E, Ellenrieder M, Gruber G, et al. Influence on load transfer of different femoral neck endoprostheses. Z Orthop Ihre Grenzgeb 2006; 144: 386-393.

16. Bieger R, Ignatius A, Reichel $\mathrm{H}$, et al. Biomechanics of a short stem: in vitro primary stability and stress shielding of a conservative cementless hip stem. J Orthop Res 2013; 31: $1180-1186$.

17. Jakubowitz E, Seeger JB, Lee C, et al. Do shortstemmed-prostheses induce periprosthetic fractures earlier than standard hip stems? A biomechanical ex-vivo study of two different stem designs. Arch Orthop Trauma Surg 2009; 129: 849-855.

18. Asaad A, Hart A, Khoo MM, et al. Frequent femoral neck osteolysis with Birmingham mid-head resection resurfacing arthroplasty in young patients. Clin Orthop Relat Res 2015; 473: 3770-3778.
19. Steens W, Skripitz R, Schneeberger AG, et al. Cementless femoral neck prosthesis CUT - clinical and radiological results after 5 years. Z Orthop Unfall 2010; 148: 413-419.

20. Bergmann G, Deuretzbacher G, Heller M, et al. Hip contact forces and gait patterns from routine activities. $J$ Biomech 2001; 34: 859-871.

21. Bergmann G, Graichen F and Rohlmann A. Hip joint loading during walking and running, measured in two patients. J Biomech 1993; 26: 969-990.

22. Bergmann G, Graichen F, Rohlmann A, et al. Realistic loads for testing hip implants. Biomed Mater Eng 2010; 20: 65-75.

23. Brand RA, Crowninshield RD, Wittstock CE, et al. A model of lower extremity muscular anatomy. $J$ Biomech Eng 1982; 104: 304-310.

24. Brand RA, Pedersen DR and Friederich JA. The sensitivity of muscle force predictions to changes in physiologic cross-sectional area. J Biomech 1986; 19: 589-596.

25. Duda GN, Schneider E and Chao EY. Internal forces and moments in the femur during walking. $J$ Biomech 1997; 30: 933-941.

26. Duda GN, Heller M, Albinger J, et al. Influence of muscle forces on femoral strain distribution. J Biomech 1998; 31: 841-846.

27. Heller MO, Bergmann G, Deuretzbacher G, et al. Musculo-skeletal loading conditions at the hip during walking and stair climbing. J Biomech 2001; 34: 883-893.

28. OrthoLoad. In: Bergmann G (ed.) Vol. 2016. Berlin: Charite Universitaetsmedizin, 2008, http:// www.OrthoLoad.com

29. Simoes JA, Vaz MA, Blatcher S, et al. Influence of head constraint and muscle forces on the strain distribution within the intact femur. Med Eng Phys 2000; 22: 453-459.

30. Brady O, Garbuz D, Masri B, et al. Classification of the hip. Orthop Clin N Am 1999; 30: 215-220.

31. Ender SA, Machner A, Pap G, et al. Cementless CUT femoral neck prosthesis: increased rate of aseptic loosening after 5 years. Acta Orthop 2007; 78: 616-621.

32. Ishaque BA, Donle E, Gils J, et al. Eight-year results of the femoral neck prosthesis ESKA-CUT. Z Orthop Unfall 2009; 147: 158-165.

33. Ries C, Schopf W, Dietrich F, et al. Anatomic reconstruction of hip joint biomechanics with the bone preserving silent micro Hip prosthesis. Z Orthop Unfall 2013; 151: 497-502.

34. Aqil A, Sheikh HQ, Masjedi M, et al. Birmingham midhead resection periprosthetic fracture. Clin Orthop Surg 2015; 7: 402-405.

35. Olsen M, Lewis PM, Waddell JP, et al. A biomechanical investigation of implant alignment and femoral neck notching with the Birmingham mid-head resection. J Arthrop 2010; 25: 112-117.

36. Aghayan S, Shepherd DE and Davis ET. A biomechanical study of the Birmingham mid head resection arthroplasty: effect of stem size on femoral neck fracture. Proc IMechE Part H: J Engineering in Medicine 2013; 227: 913-918. 